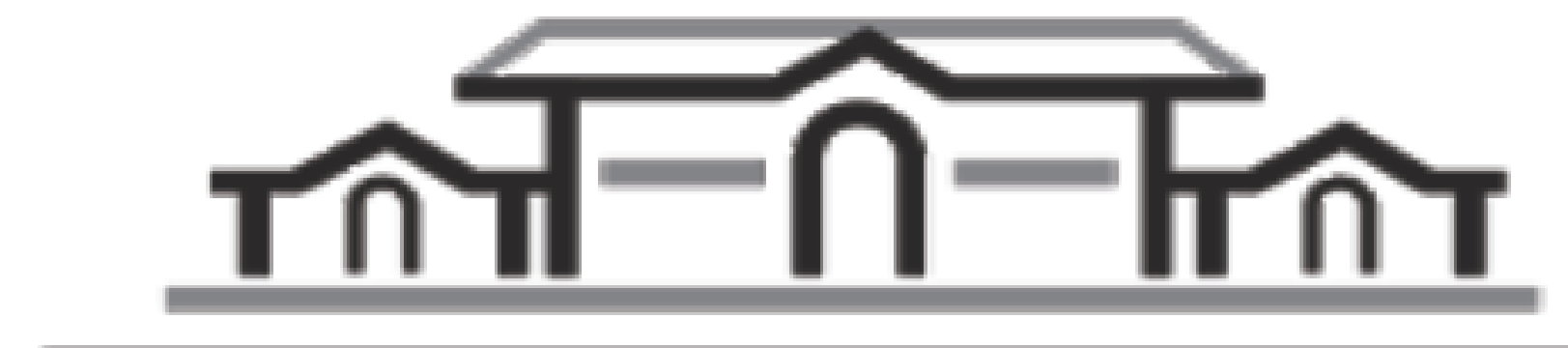

QENDRA SPITALORE UNIVERSITARE "NËNE TEREZA"

\title{
Influence of educational training course in improving the knowledge of diabetes mellitus among nurses of Diabetes Education Units in Albania.
}

\author{
Kermaj M,Ylli D, Fureraj Th, Zeqja A, Hoxha V, Ylli A \\ Endocrinology, Diabetology and Metabolism Disease Unit, “Mother Teresa” Hospital Center, University of Medicine,
} Tirana, Albania

\section{Background}

The involvement of nurses in diabetes patient education has an important contribution in the improvement in the quality of care provided. Experience and knowledge in diabetes and its management are crucial for teaching patients with diabetes effectively.
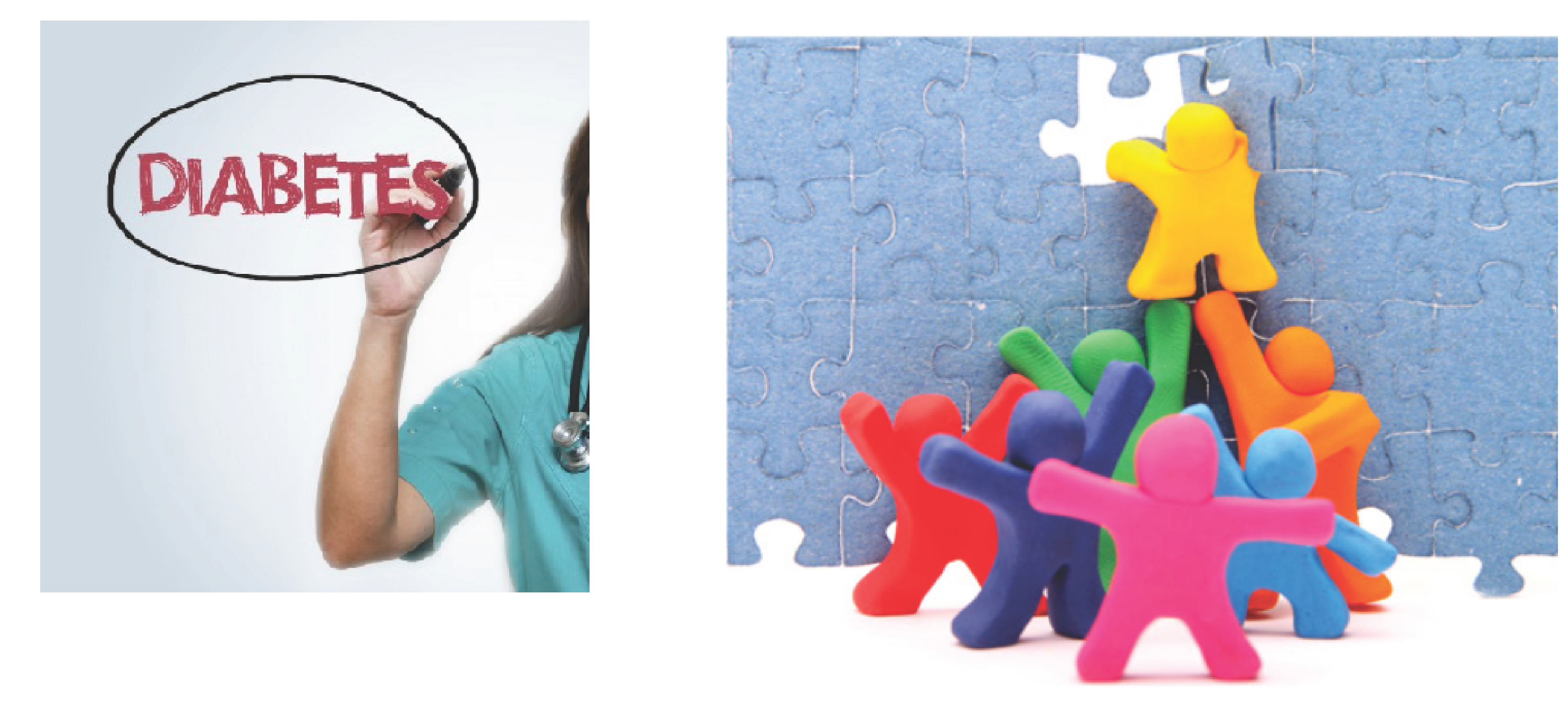

Test results before and after training

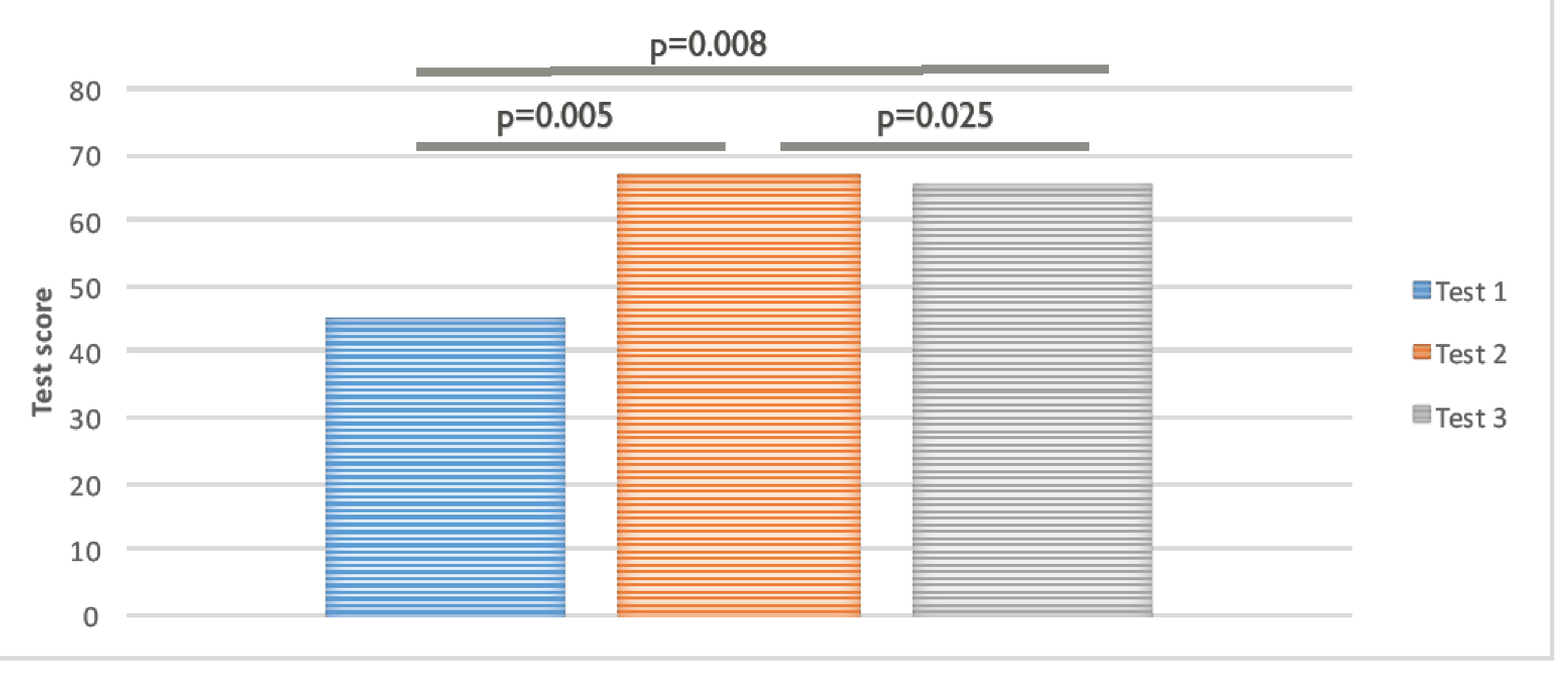

Correlation between test results and years of experience

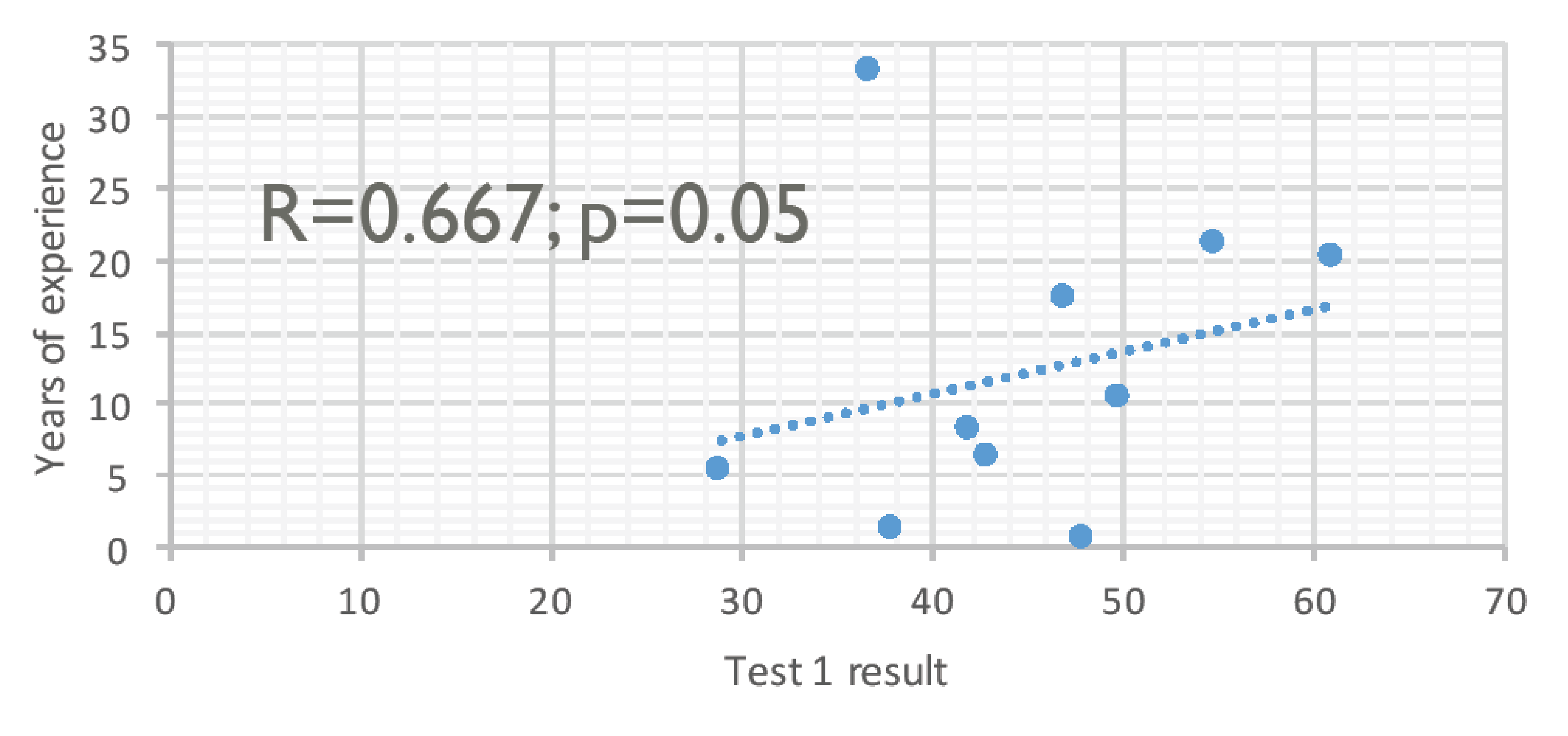

\section{Material and methods}

The aim of the study is to evaluate the effect of nurse Training Course in the improvement of the knowledge of diabetes among nurses. Ten Diabetes Education Unit's nurses, one per each Albania's regional hospital, aged from 25 to 55 years old, underwent the Training. To evaluate the diabetes knowledge a multiple-choice questionnaire was assessed, before the training ( $\mathrm{TI})$, immediately after (T2) and six months after the training (T3).

\section{Results}

The nurses, 8 women and 2 men aged $35.5 \pm 2.96$ years old (median \pm S.E.M), having $9 \pm 3.2$ years of working experience from which $5.5 \pm 3.4$ years were in endocrinology. The mean knowledge score before the training was $45 \pm 2.9$ out of 100 . It improved to $68.5 \pm 1.4$ immediately after and to $66 \pm 1.4$ points six months after the training. There was a statistically significant difference between $\mathrm{TI}$ and $T 2$ results $p=0.005$, between $T I$ and $T 3 p=$ 0.008 , and between $\mathrm{T} 2$ and $\mathrm{T} 3 \mathrm{P}=0.025$. $\mathrm{A}$ significant correlation was observed between the TI score and the working years $(r=0.667, p=0.05)$ and $\mathrm{TI}$ score and the years working in endocrinology $(r=0.729, p=0.026)$.

\section{Conclusion}

We observed an improvement of the diabetes knowledge among the nurses participating the training course and a slight knowledge decrease 6 months after the course. Only the first test result was influenced by the number of years working in endocrinology. These preliminary results suggest the importance of continuous education in improving diabetes knowledge and giving a better diabetes care 